\title{
Community Participation in Housing and Urban Development in Poor Urban Communities, Case Study of Umbadda, Khartoum
}

\author{
Muna M. Eltahir ${ }^{1}$
}

\begin{abstract}
Community participation represents a voluntary action carried out by community members who participate with each other in different kinds of work to achieve desired goals. Participation includes people's involvement in decision-making, in implementing programs, sharing in the benefits of development programs and their involvement in efforts to evaluate such programs. (Cohen, D. and Prusak).

According to Muhammad, community participation, known locally as nafeer or fazaa, is a deeply rooted ancient phenomenon in the Sudanese culture and has been common especially among traditional people in rural areas and villages, where it is usually men's domain (Muhammad, 1975). Community participation is affected by religious beliefs, ethnic and cultural backgrounds as well as laws, political environment, economic situation. Social relations (social capital), history and age of the neighborhood.

The present paper discusses community participation in Umbadda, Harra 14, a newly planned poor neighborhood in Greater Khartoum the capital of Sudan, which has a population of 5.5 million inhabitants growing at an annual rate of $5.6 \%$ per year. Data collection was based on a filed research carried out by the author in the summer of 2002 through intensive interviews with community leaders, and a structured household questionnaire.

Key words: Participation, Actors, Resources, Umbadda, Khartoum, Sudan..
\end{abstract}

ملخص

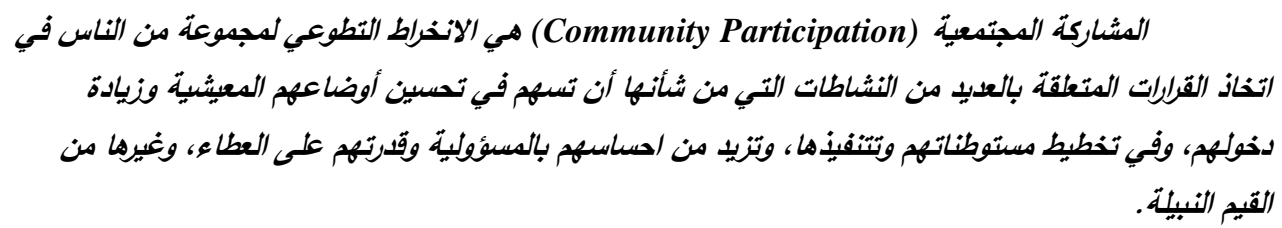

${ }^{1}$ Faculty of Eng. Sciences - Omdurman Islamic University- E-mail: mmeltahir@yahoo.com 


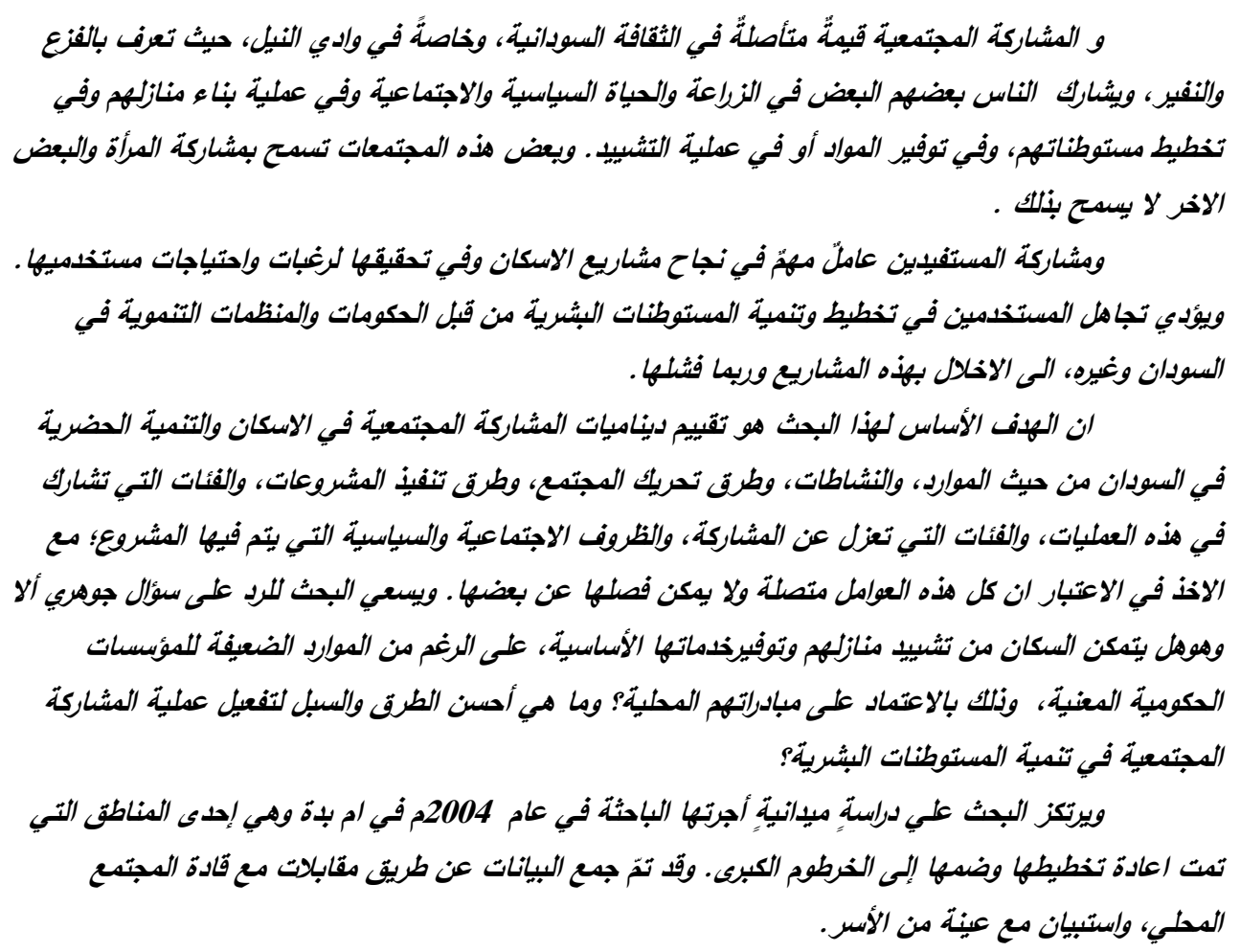

\section{Introduction}

According to a study carried out in 1988, most of Umbadda residents were from western Sudan, and especially from the Nuba Mountains ${ }^{2}$ (El Agraa, Omer M.A. and Shaddad, 1988) these findings were confirmed by the questionnaire carried out by the author in the summer of 2002: $92 \%$ of the population of the neighborhood the author surveyed (Harra 14) were Nuba who migrated from the Nuba Mountains region (Map No 1), and only $8 \%$ were from other regions of Sudan who came to live in the area after its replanning in 1988.

\footnotetext{
2 /The Nuba mountains comprise about 99 hills. Tribal groups that live on and around a hill are identified by it. This created many inter-tribal differences between them.
} 


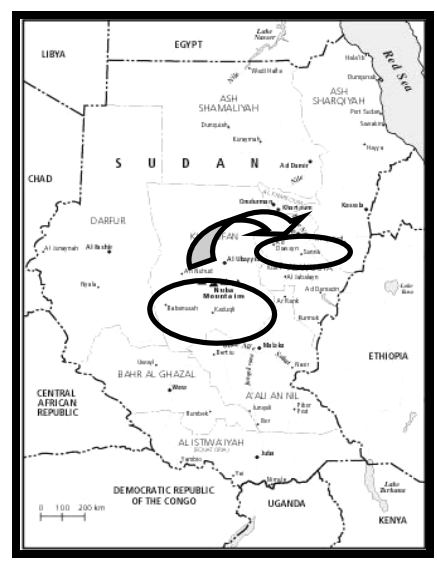

Map 1: Map of Sudan Showing the Nuba's Place of Origin and Their New Settlements in Umbadda.

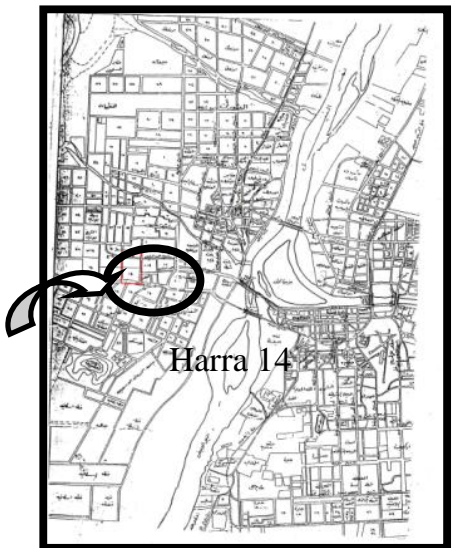

Map 2: Map of Khartoum showing the Umbadda Harra 14.

Umbadda residents are mostly internally displaced households who have migrated to Greater Khartoum from different parts of the country, at different times. Some moved during the Mahdia's regime (1885-1898), lived in some parts of the city for several decades. Others migrateed later because of drought and famines during the 1960s and after the mid-1980s, lived in squatter settlements within the city, and the rest of them moved directly to Umbadda, which was then a rapidly growing informal settlement. One family member or tribal group moved to the place, and found it convenient; they would encourage other family and tribe members to move to that place. This created tribal residential zones formed along tribal relationships, with narrow winding streets, that separate the different zones from each other, with a big open space outside these settlements used for the kambala ${ }^{3}$ dance. After replaning in 1988 , one could see that it has clear plots, wide roads, vacant plots reserved for services, and open spaces. The place reflects a great deal of poverty, which spreads its wings all over the neighborhood, but much clearer in the houses where a number of them are

${ }^{3}$ / Kambala dance is usually performed at night outside Nuba village, sometimes at a central point between two or more adjacent villages. 
Community Participation in Housing and Urban Development... Muna M. Eltahir

without boundary walls, others have low walls built with mud bricks, most houses have one or two rooms, and a rakoba ${ }^{4}$.

\section{Objective}

The primary objective of this paper is to assess the dynamics of community participation in Sudan in terms of its components, activities, resources mobilized, mobilization processes, modes of implementation, actors involved, and those who are excluded, as well as the socio-political context in which community participation takes place, bearing in mind that all these factors work together. Aiming to answer the question that forces itself: can residents fend for themselves in home construction, and depend on their own collective action in the provision of basic services, i.e. build schools, health centers and infrastructures? And what are the best means that could facilitate people's participation in developing their human settlements. Pointing out that community participation is a long time development process that creates positive as well as negative changes in people's lives, environment and attitudes.

\section{Criteria for Selection of the Case Study}

My selection of Umbadda was based on a number of reasons:

1) Difference in residents' social structure and cultural background where residents have come to live together from different places.

2) The difference in the phases through which these neighborhoods were created: because settlement of Umbadda resulted from mass movements.

3) Residents were known before replanning, which facilitated their participation in the replanning and consolidation process.

\section{Social Situation}

Most of the households are single family households, some of them had lost their male head husband, father, etc. which disrupted the social situation of most of these families, who have already lost their livestock due to different disasters. Women in Umbadda are rather aggressive; they

4/ A light shaded area used as a verandah 
perform triple roles similar to those assumed by rural women: a) a productive role as income generators, b) a reproductive role, that included bearing, looking after and educating children, c) a community management role (Moser, 1994).

\section{Community Participation in the Area}

Resident's life in Umbadda had passed through different experiences before and after replanning of their neighborhood whether in their social life, neighborhood layout, dwelling design, and participation among community members that could be divided into two types (Figure No 1):

For the purpose of this paper I will only discus community participation in private buildings after replanning.

Community Participation
after Replanning $\left\{\begin{array}{l}\begin{array}{l}\text { Community participation } \\ \text { in private buildings. }\end{array} \\ \text { Community participation } \\ \text { in public buildings } \\ \text { formal community } \\ \text { participation }\end{array}\right.$

Figure 1: Classification of Community Participation in Umbadda.

\subsection{Community Participation after Replanning}

According to a number of interviewees, peoples' social life started to change after replanning for a number of reasons:

a. Conflicts arose between residents throughout the replanning period especially when deciding on different people's eligibility to land ownership.

b. The appearance of a number of people who used to live in the other parts of the city but have built boundary walls around vacant plots, waiting for replanning to take place to come and live in the area. This made some of the residents feel uneasy about them, since they think 
Community Participation in Housing and Urban Development... Muna M. Eltahir

those people did not share with them their hard times, but got the fruits.

c. Conflicts between popular committee members and some residents on issues that surfaced during replanning.

d. Negligence of people's social and cultural background by planners.

All these factors negatively affected residents' social fabric and made community participation among them hard to achieve, except between people from the same tribal groups and between family members who didn't have as many conflicts between them.

\subsection{Community Participation in Private Buildings after Replanning}

Participation in private buildings (i.e. houses) is affected by people's social relations, economic status, skills and traditions. As I was told by a number of interviewees, most of the work, especially preparation of bricks, is done by the owner of the house and his/her close family members, mainly his nephew because, he is the one responsible for taking his uncle's revenge (tar) in case he was killed by somebody, so he is the one who should help in this process. After that walls and roof will be built by the help of other family and tribal group members in response assistance call from the owner.

After replanning, and without residents' participation, the Ministry of Engineering Affairs provided residents with a model design for their new houses that consisted of two alternating rooms and two verandahs. The design proposed two different building materials and construction techniques, which were:

a. Red brick walls with corrugated iron sheets roof.

b. Gishra wall (i.e. composed of an external wall of baked bricks and an internal one of unbaked bricks tied to it) with traditional roof.

c. The model design is common in northern and central Sudan and some call it "the railway design" because apparently it was first adopted by the Sudan Railways Company. Although it suits the climate in the area, it doesn't fit their way of life, culture, skills and knowledge, previous house design, and economic situation; which resulted in the presence of different dwelling designs after replanning, which could be described as follows: 
Type A: houses that adapted the proposed Ministry of Engineering Affairs plans partially in these houses:

a. Minimum participation was used during construction because of the introduction of construction techniques and building materials with which many residents were not familiar.

b. Rooms are properly oriented; doors and windows open to the north-south direction allowing for good natural ventilation.

c. Most of the residents who adapted these plans are from those who lived in the city for some time before moving to Umbadda or have good financial resources.

Cultural and personal changes are not easily quantifiable but have important implications especially on their dwelling layouts.

Type B: houses that didn't adapt the proposed plan, which were built through self-help efforts among family members or tribal groups:

a. Rooms are scattered within the plot (Figure No 4), some of them were not properly orientated and others are windowless but this was clarified by some interviewees who described their huts in their homeland as being windowless.

b. Most of the residents who didn't have a clear plan are those who moved directly to Umbadda from their homelands, and have limited resources.

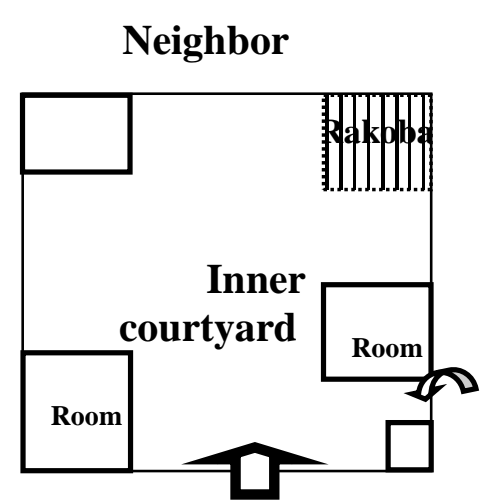

Figure 4: Houses Type B Plot with Scattered Rooms around the Plot.

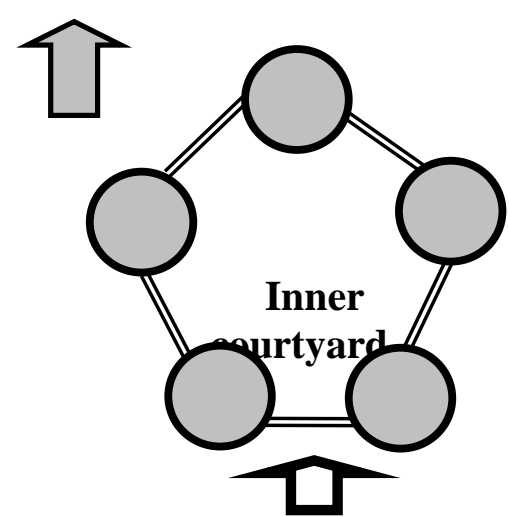

Figure 5: Traditional Nuba House with its Scattered Rooms. 
The proposed plan by the Ministry of Engineering Affairs, in spite of its good orientation and adoption of good construction technique, delayed private dwelling construction because:

a. Its construction techniques are new to residents' therefore residents couldn't use self-help to construct it and costly hired labor is needed.

b. Resident's financial ability couldn't satisfy the design requirements.

c. The proposed dwelling design doesn't satisfy their cultural needs.

Those who followed the Ministry of Engineering's plan started by building a room and a verandah, with walls built using either red bricks or red brick from the outside and mud bricks from the inside, known locally as Gishra walls. While those who did not adopt the proposed plan typically started by building a room or two at one end of the plot using adobe, i.e. clay soil stabilized in some cases with straw. In many cases the soil was obtained from the road in front of their houses causing great damage to the unpaved street.

A number of observations can be made about houses in Umbadda:

a. Rooms were oriented in different directions, using minimum doors and windows 5 .

b. To avoid surface floods in the area destroying their houses again, people chose the highest point within their plots to build their rooms.

Walls are not straight and do not have a unified height because they use simple construction techniques and primitive instruments.

Studying the houses in this area, and going back to the typical traditional houses of the Nuba people, I conclude that residents were confused by the Ministry's plan, that introduced building materials and construction techniques that were unknown to them. This has resulted in:

a. No clear design in most of the houses especially among those who moved directly to the area.

b. Lack of confidence within residents to use their previous building knowledge.

$5 /$ Most huts in the Nuba area are windowless and have a single entrance (According to interview with the popular committee representative at the local council, confirmed by the head of the council Mr. Mahgoub ). 
c. Self-help in private buildings as well as public building is limited in the area because of the introduction of new building materials and techniques.

\section{Obstacles to Community Participation}

A number of constraints to community participation have been encountered in this community at its different levels. These could be listed as follows:

Weak social relations: The community in this part of Umbadda seems to be homogeneous, being from the same origin which is western Sudan; but interviews revealed that there are great conflicts between them caused by a number of reasons, e.g. conflicts during replanning, in addition to differences related to their sub-tribal groups. These factors together helped in the weakening of social capital that could help community members to participate fully in development efforts, and have direct effects on the development of individual houses and their neighborhood.

Limited resources: Lack of experience, skills, and knowledge; weak social relations, in addition to residents' lack of time because their main priorities are to feed their families not to attend meetings or to participate in community development projects. Furthermore, lack of water connections within their homes or at walking distances from it made people spend substantial time and resources to provide water for their families.

Cultural obstacles; Nuba's culture which restricts participation among family members to the nephews only, and exclude women from contributing to participatory work, leaving out an important helping hand from contributing to development efforts.

\section{Concluding Remarks}

For any community participatory work to take place there must be some form of resources, whether financial, materials, knowledge or human resources but in this area there is lake of material and knowledge resources 
$\underline{\text { Community Participation in Housing and Urban Development... } \quad \text { Muna M. Eltahir }}$

instead wide-spread poverty could be viewed as an overarching constraint to the success of community participation in the area.

Community participation in building individual houses was limited by providing residents with a standard layout of the Ministry of Engineering that doesn't satisfy their cultural backgrounds, as well as their economic abilities or building knowledge. This layout was totally different from their previous dwelling designs $^{6}$, which have been described as "striking because more skill, care and indeed art go into their making than with any other Sudanese tribe".

\section{Recommendations to Improve Community Participation in the Area}

A number of recommendations are proposed in order to develop this part of the city:

1. Skills and knowledge have to be developed and used, more participation in development efforts could then be attained by residents themselves, and a more interesting built environment would have resulted.

2. development of a plan that suite their social way of life should be made available at the locality office for residents to utilize

3. Local authorities should help in reducing tensions between community members themselves, and between them and their popular committee, which will improve people's social capital, that may encourage community members to participate willingly in communal projects.

4. Develop an active network of neighborhood organizations, train them on different issues and skills that will increase their access to resources, and direct their resources and energies to developing their neighborhood.

\footnotetext{
${ }^{6}$ / Nuba, Dalang (Kordofan,): The typical traditional house of the Nuba people living in and around Dalang, is of the central courtyard type. A hedge is used as a boundary wall and connects the ring of huts surrounding the courtyard. Entry to compound is through an arched gate, and the arch is made out of freshly cut tree branches. (Mahgoub, 1987.

Nuba, Kadugli: the typical house of the Nuba tribes inhabiting the areas around Kadugli has a central courtyard surrounded by a $1.5 \mathrm{~m}$ high boundary wall constructed of stone without mortar (Mahgoub, 1987 ).
} 
5. Develop human resources, i.e. knowledge and use of new and improved building techniques by facilitating formal training on those techniques and methods.

6. Women must have access to education, training and finance, to enable them to become economically productive, and be prepared to play significant roles in the development of their neighborhood

\section{Refrences}

[1] Anisur, Rahman. 1993. People Self-Development, Perspectives on Participatory Action Research: Zed Books.

[2] Cohen, D. and Prusak, L. 2001 In Good Company. How social capital makes organizations work, Boston, Ma: Harvard Business School Press.

[3] El Agraa, Omer M.A. and Shaddad M.Y. 1988. "Housing Rentals in the Sudanese Capital" Khartoum University Press.

[4] Eltahir, Muna M. 2001. "Potentials of community participation: case studies from Diar Al-Shigia, Sudan". Sudan National Center for Research, $5^{\text {th }}$ Scientific Conference: Housing and Development in Sudan. Khartum, 17-21.

[5] Kaafeel, Abd Allah, 2001. "The Role of Popular and Voluntary Governance in Municipal Projects with reference to Khartoum Sudan (1991-1999)". Arab Urban Development Institute.

[6] Moser, Caroline 1994. Gender Planning and Development: Theory, Practice and Training. Routledge.

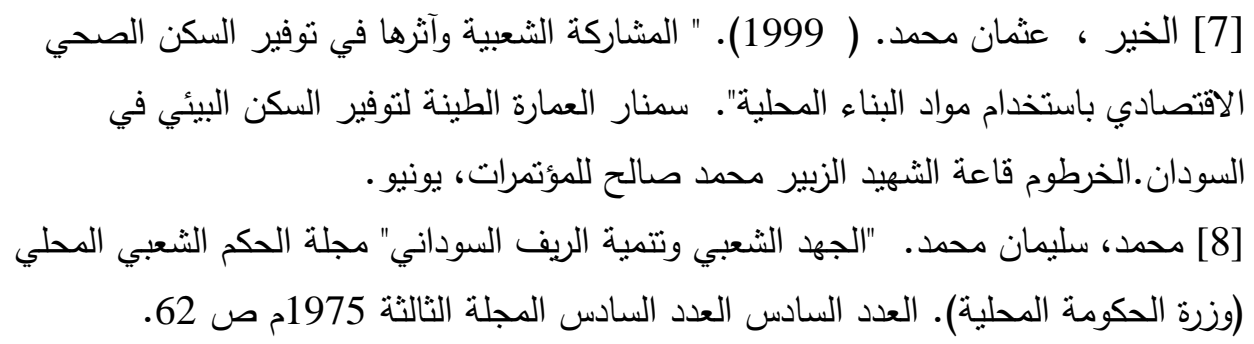

